\title{
Ejaculate size varies with remating interval in the grasshopper Chorthippus parallelus erythropus (Caelifera: Acrididae)
}

\author{
KLAUS REINHARDT
}

Department of Animal and Plant Sciences, The University of Sheffield, Sheffield, UK, e-mail: k.reinhardt@sheffield.ac.uk

Key words. Caelifera, ejaculate size, remating interval, sperm replenishment, testis size

\begin{abstract}
The number of sperm a male ejaculates is influenced, among other factors, by male age, time since last copulation and possibly a combination of both. Males of Chorthippus parallelus erythropus were subjected to three successive matings in which males had a remating interval of either one or three days. The first ejaculate was very variable. It contained a mean of 433,000 sperm. If there was a one-day interval between matings, the second and third ejaculate comprised $16-19 \%$ of the number of sperm in the first ejaculate, respectively. Its sister taxon, the subspecies Chorthippus p. parallelus showed a similar second ejaculate size but the third ejaculate further declined to $8-10 \%$ compared to the first. If there were three days between matings, second and third ejaculates comprised $148.3 \%$ and $63.1 \%$ of the number of sperm in the first ejaculate in Chorthippus p. erythropus. This was markedly different to two individuals of Chorthippus p. parallelus where second and third ejaculates comprised 597\% and $416 \%$ of the first. It is speculated that this indicates an overall higher sperm production because testis size was also larger in Chorthippus p. parallelus than Chorthippus p. erythropus. The results also show that theoretical models on sperm allocation may underestimate the rate and age-dependency of sperm replenishment.
\end{abstract}

\section{INTRODUCTION}

In many insect species the number of sperm per ejaculate, henceforth ejaculate size, is considered an important male fitness trait (Parker, 1970; Simmons, 2001). Two parameters that are often correlated with ejaculate size are male age and remating interval, both of which may affect ejaculate size via sperm production. The effect of male age on ejaculate size is addressed using two methods. In the first, the number of sperm transferred is analysed with respect to the age of males at their first mating, and usually an increase is found (Hayashi, 1999; LaMunyon, 2000; LaMunyon \& Huffmann, 2001; Reinhardt, 2001; Wedell \& Ritchie, 2004). However, this increase may merely reflect sperm accumulation before ejaculation (LaMunyon, 2000). Such accumulation may be caused by an age-independent, or an age-dependent rate of sperm production. Therefore, the second protocol, in which males are mated repeatedly with a recovery period between matings (e.g. Pitnick \& Markow, 1994; Cook \& Gage, 1995; Watanabe et al., 1998; Wedell \& Ritchie, 2004; Bailey \& Nuhardiyati, 2005; Marcotte et al., 2005) is more likely to reveal age-dependent changes in ejaculate size. This method has the drawback that the period of sperm replenishment interferes with male age and remating interval. For example, in most species sperm numbers per ejaculate rapidly decrease over successive matings if the remating interval is short (Wedell et al., 2002).

Selection can be expected to lead to a correlation between the partitioning of available sperm across successive matings (sperm allocation) and natural mating frequencies. Males of frequently mating species are likely to spend only a proportion of their available sperm across successive copulations (Reinhold et al., 2002) or alternatively, may have high sperm replenishment rates between successive matings. It is argued that high spermatogenic activity is reflected in large testis size (Ball \& Parker, 1996; Schärer et al., 2004; but see Froman \& Feltman, 1998; Wistuba et al., 2003) and therefore, an indicator of sperm production rate and natural mating rate.

Here I study ejaculate size of male $C$. p. erythropus that are mated in rapid succession, i.e. with little replenishment. I also measure ejaculate size when there is a replenishment interval between matings. For illustrative reasons I also report the few data that became available on its sister taxon, the grasshopper Chorthippus parallelus parallelus because the two subspecies form a hybrid zone in southern Europe (Hewitt, 1988; Butlin, 1998; Hewitt, 2001, reviewed Butlin, 1998) and the two subspecies have diverged in several reproductive traits including mate searching, female sperm handling and testis size (Neems \& Butlin, 1993; Tregenza et al., 2000a,b, 2002; Reinhardt, 2006). This comparison and the differences in testis size resulted in the speculation that the two subspecies may differ in sperm allocation.

\section{MATERIAL AND METHODS}

\section{Study species}

C. p. erythropus is restricted to the Iberian Peninsula. It is mesophilic to hygrophilic, i.e. avoids dry habitats. It has a univoltine life cycle. In captivity females become sexually receptive 3 to 10 days after eclosion. Females mate repeatedly in the laboratory. As in all grasshoppers, sperm is transferred via a spermatophore. Sperm mixing in the female sperm storage organ could not be excluded in two related taxa, $C$. p. parallelus and C. biguttulus (Reinhardt, 2000) and so ejaculate size is likely to be an important fitness parameter in C. p. erythropus. 
TABLE 1. Divergence in reproductive traits across three populations of the grasshopper Chorthippus parallelus. Data are presented as means \pm s.d. Sample sizes are in parentheses. A generalized linear model (Dispersion parameter 0.713, 27.8\% of the variation explained) found a difference in testis size between populations $\mathrm{J}$ and $\mathrm{P}(\mathrm{t}=5.223, \mathrm{p}<0.001)$ but not between $\mathrm{E}$ and $\mathrm{J}(\mathrm{t}=0.551, \mathrm{p}$ $>0.5)$.

\begin{tabular}{lccc}
\hline \multirow{2}{*}{ Trait } & \multicolumn{3}{c}{ Population } \\
\cline { 2 - 4 } & $\mathrm{E}$ & $\mathrm{P}$ & $\mathrm{J}$ \\
\hline First ejaculate size $\left(\times 10^{3}\right)$ & $433.6 \pm 399.9(13)$ & $292.9 \pm 305.6(3)$ & $276.5 \pm 190.4(9)$ \\
Male dry weight $(\mathrm{mg})$ & $24.31 \pm 3.91(25)$ & $28.85 \pm 4.39(31)$ & $32.0 \pm 4.1(20)$ \\
Testis dry weight $(\mathrm{mg})$ & $1.19 \pm 0.22(25)$ & $1.53 \pm 0.27(31)$ & $1.2 \pm 0.33(20)$ \\
\hline
\end{tabular}

The mating frequency in the field is unknown but sexual encounters occur frequently (Neems \& Butlin, 1993).

\section{General rearing}

The study was carried out in a field laboratory in Saillagouse (France), in the Eastern Pyrenees, close to the centre of the above mentioned hybrid zone (Butlin, 1998). All individuals were collected as nymphs from near the locus typicus, Eyne, (Faber, 1958) (locality EY according to Butlin \& Hewitt, 1985). Virgin adults were obtained by daily collecting all emerged adults in the mass rearing cages. Freshly cut grass blades of Dactylis glomerata were provided as food every two to three days. For further rearing details see Reinhardt \& Köhler (1999), Reinhardt et al. (1999), Reinhardt (2001, 2006).

The males of the two populations originate from the northern end of the hybrid zone (Puyvalador North, PU in Butlin and Hewitt, 1985) henceforth called P, and from central Europe (Jena, eastern Germany: J).

\section{Mating trials and sperm counts}

In order to reduce the possible effect of the number of competitor males on ejaculate size (Reinhardt, 2001) newly eclosed males were kept in groups of more than ten, but less than twenty, until used in the mating trials. Males were subjected to their first mating when $6 \pm 1$ days old. Males were randomly allocated to a remating interval of either one or three days. Thus, males were mated at ages of 6,7 and 8 days, or $6,9,12$ days. Virgin females aged 4-12 days were offered individually to a male in a cage. If copulation did not occur within one hour a different female was offered. After mating, males were returned to individual cages and females were used for the sperm count protocol. Males were kept individually between matings. The temperature during the mating protocols was between 29 and $30.5^{\circ} \mathrm{C}$.

Only three males from population $\mathrm{P}$ were available at the same time as the experiment with $C$. p. erythropus was carried out. J males were subjected to the one-day interval treatment in the laboratory in Jena.

Sperm numbers were analyzed as previously described (Reinhardt et al., 1999; Reinhardt, 2001, 2006). Briefly, the spermatheca and its duct were removed from the female within 1 to $60 \mathrm{~min}$ after mating. The spermatheca was ruptured in distilled water and the released sperm homogenized by drawing the solution twenty times up and down using a pipette. A drop of the homogenized solution was pipetted onto a haemocytometer, the number of sperm counted in three quadrats and their means were multiplied by the dilution.

\section{Testis size}

Field-collected males were left for two hours without food, then dissected and their testes removed (sample sizes in Table 1). Dissected males and testes were dried separately in an oven at ca. $200^{\circ} \mathrm{C}$ for $2 \mathrm{~h}$ - the time necessary to achieve a constant dry weight. The testes were weighed on a mechanical spring balance to the nearest $0.05 \mathrm{mg}$. The same procedure was carried out for males of the $\mathrm{P}$ and $\mathrm{J}$ populations (see Table 1 for sample sizes).

\section{Statistical analysis}

All analyses were carried out using S-PLUS (Crawley, 2002). Ejaculate size was analysed using a linear mixed model with log-transformed sperm numbers as the dependent variable and mating interval and mating order as explanatory variables. Male identity was used as a random factor in which mating order was nested. This procedure corresponds to a repeated-measures ANOVA (Crawley, 2002).

Testis size was analysed as testis dry weight across all three populations. Testis size may scale non-linearly with body size making the use of relative testis weight (\% body weight, or gonadosomatic index) invalid. I used a generalized linear model with testis dry weight as the dependent and population as the independent variable (factor). Because males differed in dry weight across populations I run the models with and without male dry weight nested in population as a covariable.

\section{RESULTS}

Ejaculate size was affected by the interaction of mating order and remating interval (order $\mathrm{x}$ interval: $0.229 \pm$ $0.103, \mathrm{t}=2.232, \mathrm{p}=0.037$; Fig. 1). Specifically, this interaction was characterised by an ejaculate size decrease over successive matings with a one day interval (Linear mixed effects model, order effect: $-1.100 \pm 0.285$ (s.e.), $\mathrm{t}=-3.87, \mathrm{p}=0.0009)$ and an increase with a three-day interval between the first and the second mating, i.e. between age 6 and 9. There was no increase between age 9 and 12 (Fig. 1).

Ejaculate sizes were similar in mean and variation (as indicated by the large standard deviations - Table 1) to those measured in $\mathrm{J}$ males under similar or the same laboratory conditions (Reinhardt et al., 1999, Reinhardt, 2001, 2006, Table 1). In order to account for the inter-male variability in the first ejaculate, ejaculate sizes in the second and third mating are presented graphically as the proportion of the first ejaculate. With a one-day remating interval, the second and third mating resulted in ejaculate sizes of $16.8-20.1 \%$ of the first ejaculate (Fig. 1). One P and $9 \mathrm{~J}$ males showed a similar tendency to reduce the size of the second ejaculate and to further reduce that of the third ejaculate (Fig. 1).

With a three-day remating interval, successive ejaculates of the second and the third mating averaged (mean) $148.3 \%$ and $63.1 \%$ of the first ejaculate, respectively. This differed greatly from the two P males whose second and third ejaculates represented $597.3 \%$ and $416.4 \%$ respectively, of their first ejaculate. It was not possible to compare statistically the absolute sperm numbers, but 


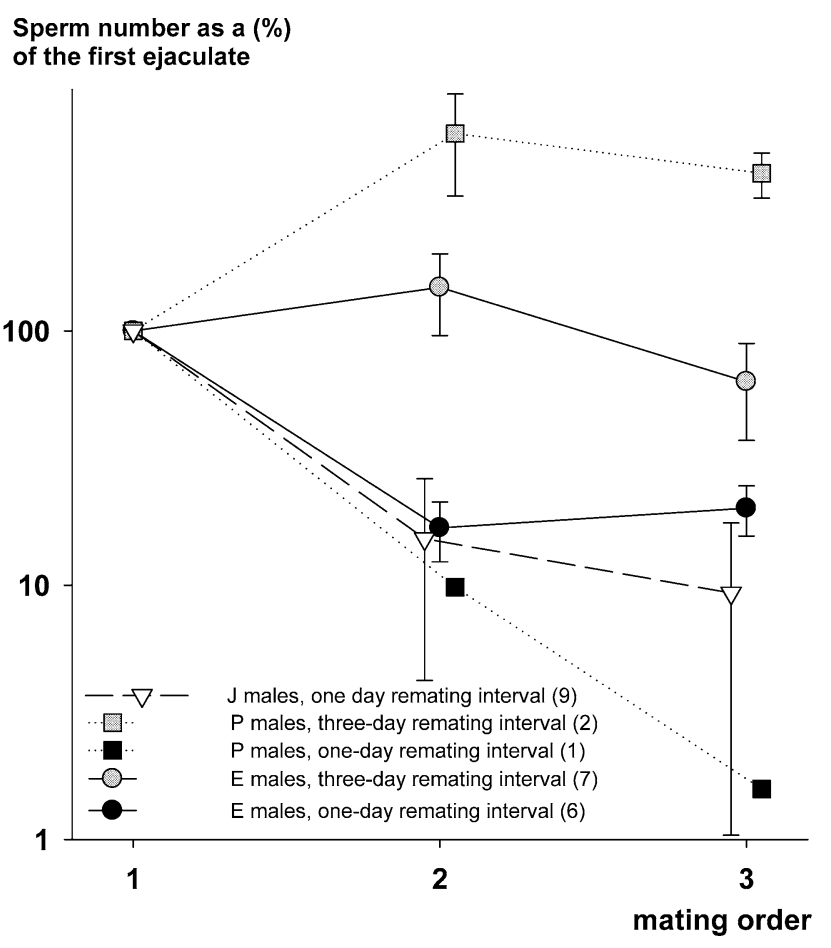

Fig. 1. The trends in sperm numbers ejaculated in three successive matings in Chorthippus parallelus (means \pm s.e.). Black symbols denote an interval of one day between matings, grey symbols three days. Sperm numbers are presented as a percentage of the first ejaculate and are all for within-population matings. Note the logarithmic scaling of the y-axis.

averaging the sum of the second and third mating showed that ejaculate sizes were almost twice as high in $\mathrm{P}$ males (969,400 sperm) than in C. p. erythropus $(527,500)$.

Testes size was larger in $\mathrm{P}$ males than $C$. p. erythropus but did not differ between $C$. p. erythropus and J males (Table 1). The same held true when testis size was corrected for the dry weight of males from the same population (generalized linear model, dispersion parameter $0.713,39.8 \%$ of the variation explained, $C$. p. erythropus vs. J males : $\mathrm{t}=-1.764, \mathrm{p}>0.09$, J vs. P males: $\mathrm{t}=2.171$, $\mathrm{p}<0.03)$. Male dry weight affected testis size only in the J population $(\mathrm{t}=3.254, \mathrm{p}<0.002)$.

\section{DISCUSSION}

\section{Sperm numbers in successive matings}

Declines in ejaculate size across matings in rapid successions are traditionally explained as either an insufficient regeneration of the male sperm supply (Wedell et al., 2002) or a strategic allocation of a fixed available number of sperm (e.g. Reinhold et al., 2002). Averaging across a set of females ranging in quality, Reinhold et al. (2002) predicted that $48 \%, 34 \%, 16 \%$ and $1.5 \%$ of sperm are allocated across four matings, or approximately $90 \%$, $40 \%, 25 \%$ and $<10 \%$ when a replenishment of $10 \%$ of the sperm was assumed between matings. In the successive matings in a leafhopper, separated by only $5 \mathrm{~min}$, and therefore excluding the possibility of sperm replenishment, the second and third ejaculates were $11 \%$ and $6 \%$ of the first mating (Bailey \& Nuhardiyati, 2005), corre- sponding to successive sperm allocations of $85.5 \%, 9.4 \%$ and $5.2 \%$.

My data on C. p. erythropus correspond more closely to the empirical data of Bailey \& Nuhardiyati (2005) than the theoretical estimates. If, for simplicity, all three populations of $C$. parallelus are combined, and it is assumed that no sperm were retained, sperm allocation to the three ejaculates should be $73-89 \%, 9-15 \%$ and $1.8-15 \%$ for the first, second and third mating, respectively. However, when there was a one day interval between matings a steady decrease in ejaculate size across three copulations was observed only in $\mathrm{P}$ and $\mathrm{J}$ males. In C. p. erythropus the third ejaculate contained a similar number of sperm to the second, ca. $20 \%$ of the first. This may be because of strategic ejaculation (retaining some sperm for later matings) or sperm replenishment over one day. As strategic ejaculation predicts a decrease in successive ejaculates (e.g. Reinhold et al., 2002) the similarity in relative sperm numbers ejaculated in the second and the third mating is more likely to reflect sperm replenishment. The similarity between the second and the third ejaculate suggests a replenishment rate of about $20 \%$ per day in 6-day old $C$. p. erythropus males.

\section{Male age and sperm production}

I used the method of repeatedly mating a male of known age in order to measure sperm production rates rather than the number of accumulated sperm. If there is an age-independent rate of sperm production one can use a replenishment rate, i.e. sperm production rate, of $20 \%$ to predict ejaculate sizes at particular ages. C. p. erythropus males on day 9, i.e. three days after their first mating, should ejaculate an amount of sperm equivalent to about $60 \%$ of the first ejaculate. On day 12 , i.e. after six days of replenishment, this figure should be about $120 \%$ of the first ejaculate. However, on days 9 and 12 the average ejaculate sizes were $148.3 \%$ and $63.1 \%$ of the first ejaculate. This suggests that sperm production in $C . p$. erythropus is age-dependent: replenishment increases towards day 9 and decreases thereafter. Both $\mathrm{P}$ males with a three-day remating interval also showed a peak at around day 9, although both had much higher ejaculate sizes at the second and third mating (relative to the first) than any of the C. p. erythropus males. This suggests that the time of the peak in sperm production may be independent of the rate of sperm production. It remains to be seen whether these two $\mathrm{P}$ males are typical of the entire population or are just outliers.

Male-age related peaks in ejaculate size, and therefore presumably in sperm production rate, are also reported for other insects (e.g. Wedell \& Ritchie, 2004; Bailey \& Nuhardiyati, 2005). The existence of such peaks suggests that males are either selected to have a peak sperm production, which could be adaptive if males in the wild eclose before females. Alternatively, natural selection does not act on sperm production rate and the peak is the result of a developmental constraint early in life. The present data neither supports or refutes either of these two ideas. However, models of the evolution of sperm allocation (e.g. Parker, 1998; Reinhold et al., 2002; Williams et 
al., 2005) may benefit from the inclusion of agedependent sperm production rates and, as is known to occur in a planthopper (Bailey \& Nuhardiyati, 2005), an age-dependent sperm allocation strategy. The present data also indicate that replenishment or sperm production rates can be magnitudes higher than used in theoretical models (reviewed in Reinhold et al., 2002).

\section{The effect of sperm age}

Above I have accepted the traditional paradigm of sexual selection that all sperm of an ejaculate have the same value. However, this is unlikely because of sperm cell age (Siva-Jothy, 2000). Recently it was shown in house crickets that the older sperm within an ejaculate are less likely to be stored by a female (Reinhardt \& SivaJothy, 2005). This suggests that the number of old sperm that have accumulated before ejaculation play no part in fertilisation. However, if in C. parallelus erythropus most of the sperm is ejaculated during copulation, the replenished sperm will be young and as predicted have a higher fertilisation success than older sperm of a competing male. Therefore, it remains to be tested whether the fewer but younger sperm in ejaculates produced in rapid succession are indeed at a selective disadvantage.

ACKNOWLEDGEMENT. This project was financed by the European Union through a Marie Curie Fellowship to KR. I am very grateful to J. Krobbach for technical help.

\section{REFERENCES}

Bailey W.J. \& Nuhardiyati M. 2005: Copulation, the dynamics of sperm transfer and female refractoriness in the leafhopper Balclutha incisa (Hemiptera: Cicadellidae: Deltocephalidae). Physiol. Entomol. 30: 343-352.

Ball M.A. \& Parker G.A. 1996: Sperm competition games: external fertilization and "adaptive infertility". J. Theor. Biol. 180: $141-150$.

ButLin R.K. 1998: What do hybrid zones in general, and the Chorthippus parallelus zone in particular, tell us about speciation? In Howard D.J. \& Berlocher S.H. (eds): Endless Forms. Species and Speciation. Oxford University Press, New York, pp. 367-378.

Butlin R.K. \& Hewitt G.M. 1985: A hybrid zone between Chorthippus parallelus parallelus and Chorthippus parallelus erythropus (Orthoptera: Acrididae): morphological and electrophoretic characters. Biol. J. Linn. Soc. 26: 269-285.

CooK P.A. \& Gage M.J.G. 1995: Effects of risks of sperm competition on the numbers of eupyrene and apyrene sperm ejaculated by the moth Plodia interpunctella (Lepidoptera: Pyralidae). Behav. Ecol. Sociobiol. 36: 261-268

Crawley M.J. 2002: Statistical Computing. An Introduction to Data Analysis Using S-Plus. Wiley \& Sons, New York, 772 pp.

FABER A. 1958: Chorthippus erythropus n. sp., ein nächster Verwandter der Gemeinen Grasschrecke (Ch. longicornis (Latr.) Orthopt. Acrid.). Stuttg. Beitr. Naturk. 16: 1-8.

Froman D.P. \& Feltman A.J. 1998: Sperm mobility: a quantitative trait of the domestic fowl (Gallus domesticus). Biol. Reprod. 58: 379-384.

HAYASHI F. 1999: Ejaculate production schedule and the degree of protandry in fishflies (Megaloptera: Corydalidae). Funct. Ecol. 13: 178-189.
HewitT G.M. 1988: Hybrid zones - natural laboratories for evolutionary studies. Trends Ecol. Evol. 3: 158-167.

HewitT G.M. 2001: Speciation, hybrid zones and phylogeography - or seeing genes in space and time. Molec. Ecol. 10: $537-549$.

LaMunYon C.W. 2000: Sperm storage by females of the polyandrous noctuid moth Heliothis virescens. Anim. Behav. 59: 395-402

LaMunYon C.W. \& HufFmann T.S. 2001: Determinants of sperm transfer by males of the noctuid moth Heliothis virescens. J. Insect Behav. 14: 187-199.

Marcotte M., Delisle J. \& McNeil J.N. 2005: Impact of male mating history on the temporal sperm dynamics of Choristoneura rosaceana and C. fumiferana females. J. Insect Physiol. 51: $537-544$.

Neems R.M. \& Butuin R.K. 1993: Divergence in mate finding behaviour between two subspecies of the meadow grasshopper Chorthippus parallelus (Orthoptera: Acrididae). $J$. Insect Behav. 6: 421-430.

PARKER G.A. 1970: Sperm competition and its evolutionary consequences in the insects. Biol. Rev. 45: 525-567.

PARKER G.A. 1998: Sperm competition and the evolution of ejaculates: Towards a theory base. In Birkhead T.R. \& Moller A.P. (eds): Sperm Competition and Sexual Selection, Academic Press, New York, pp. 3-53.

Pitnick S. \& Markow T.A. 1994: Male gametic strategies: sperm size, testes size, and the allocation of ejaculate among successive mates by the sperm-limited fly Drosophila pachea and its relatives. Am. Nat. 143: 785-819.

REINHARDT K. 2000: Variation in sperm precedence in Chorthippus grasshoppers. Physiol. Entomol. 25: 324-329.

REINHARDT K. 2001: Determinants of ejaculate size in a grasshopper (Chorthippus parallelus). Behav. Ecol. Sociobiol. 50: 503-510.

REINHARDT K. 2006: Sperm numbers vary between inter- and intra- population matings of the grasshopper Chorthippus parallelus. Biol. Lett. 2: 239-241.

REINHARDT K. \& KöHLER G. 1999: Costs and benefits of mating in the grasshopper Chorthippus parallelus (Caelifera: Acrididae). J. Insect Behav. 12: 283-293.

ReinhaRdT K. \& Siva-Jothy M.T. 2005: An advantage for young sperm in the house cricket, Acheta domesticus. Am. Nat. 165: 718-723.

Reinhardt K., KöHLer G. \& Schumacher J. 1999: Females of the grasshopper Chorthippus parallelus (Zett.) do not remate for fresh sperm. Proc. R. Soc. Lond. (B) 266: 2003-2009.

Reinhold K., Kurtz J. \& Engqvist L. 2002: Cryptic male choice: sperm allocation strategies in a stochastic world. $J$. Evol. Biol. 15: 201-209.

Schärer L., LAdURner P. \& Rieger R.M. 2004: Bigger testes do work more: experimental evidence that testis size reflects testicular cell proliferation activity in the marine invertebrate, the free-living flatworm Macrostomum sp. Behav. Ecol. Sociobiol. 56: 420-425.

Simmons L.W. 2001: Sperm Competition and its Evolutionary Consequences in the Insects. Princeton University Press, Princeton, $448 \mathrm{pp}$.

Siva-Jotнy M.T. 2000: The young sperm gambit. Ecol. Lett. 3: 172-174.

Tregenza T., Pritchard V.L. \& Butlin R.K. 2000a: The origins of premating reproductive isolation: testing hypotheses in the grasshopper Chorthippus parallelus. Evolution 54: $1687-1698$ 
Tregenza T., Pritchard V.L. \& Butlin R.K. 2000b: Patterns of divergence between populations of the meadow grasshopper, Chorthippus parallelus. Evolution 54: 574-585.

Tregenza T., Pritchard V.L. \& Butlin R.K. 2002: The origins of postmating reproductive isolation: testing hypotheses in the grasshopper Chorthippus parallelus. Popul. Ecol. 44: 137-144.

Watanabe M., Wiklund C. \& Bon'No M. 1998: The effect of repeated matings on sperm numbers in successive ejaculates of the cabbage white butterfly Pieris rapae (Lepidoptera: Pieridae). J. Insect Behav. 11: 559-570

Wedell N., Gage M.J.G. \& Parker G.A. 2002: Sperm competition, male prudence and sperm-limited females. Trends Ecol. Evol. 17: 313-320.
Wedell N. \& Ritchie M. 2004: Male age, mating status and nuptial gift quality in a bushcricket. Anim. Behav. 67: $1059-1065$.

Williams P.D., Day T. \& CAmeron E. 2005: The evolution of sperm-allocation strategies and the degree of sperm competition. Evolution 59: 492-499.

Wistuba J., Schrod A., Greve B., Hodges J.K., Aslam H., WeinBauer G.F. \& LuetJens C.M. 2003: Organization of seminiferous epithelium in primates: relationships to spermatogenic efficiency, phylogeny, and mating system. Biol. Reprod. 69: 582-591.

Received January 19, 2007; revised and accepted April 20, 2007 